\title{
ANALYSIS OF A METAL MATRIX COMPOSITES AUTOMOTIVE COMPONENT
}

\author{
N. Fatchurrohman ${ }^{1 *}$, S. Sulaiman ${ }^{2}$, S.M. Sapuan ${ }^{2}$, M.K.A. Ariffin ${ }^{2}$ \\ and B.T.H.T. Baharuddin ${ }^{2}$ \\ ${ }^{1}$ Faculty of Manufacturing Engineering, Universiti Malaysia Pahang, \\ 26600 Pekan, Pahang, Malaysia \\ *Email: n.fatchurrohman@gmail.com; fatchurrohman@ump.edu.my \\ Phone: +6094245802; Fax: + 6094245888 \\ ${ }^{2}$ Department of Mechanical and Manufacturing Engineering, \\ Faculty of Engineering, Universiti Putra Malaysia, \\ 43400 UPM Serdang, Selangor, Malaysia
}

\begin{abstract}
This study presents an implementation of concurrent engineering (CE) and an analytical network process to form a new rating method as part of the manufacturing process and material analysis in the product development environment. The proposed procedure is referred to as a concurrent network $(\mathrm{CN})$. It is planned for $\mathrm{CN}$ to carry out simultaneous analysis of all aspects of product elements by using CE strategy. Furthermore, CN enables interdependence and interrelationship analysis between product elements by implementing ANP. In this study, $\mathrm{CN}$ is utilized for the manufacturing process and material analysis of a metal matrix composites (MMCs) automotive component which is the brake disc. The results show that by using $\mathrm{CN}$, all the product parameters can be analyzed comprehensively and the importance weights of the product parameters with regard to the MMCs brake disc performance are obtained. It is concluded that in the manufacturing process cluster the primary process parameter has the highest score, while in the material cluster the ranking is dominated by mechanical properties. This means that these sub-conceptual parameters are the most important ones to consider in order to achieve the required performance of the product.
\end{abstract}

Keywords: Product development; concurrent engineering; analytical network process; metal matrix composites; automotive component; brake disc.

\section{INTRODUCTION}

Concurrent engineering (CE) is a philosophical strategy which refers to the product development process by which a product and its manufacturing plan are developed simultaneously, cross-functional activities are performed to achieve integration, and the voice of the customer is prioritized in the product development [1-3]. CE is a direct philosophy, but it has proven to be a powerful PD strategy [4, 5]. As a result of implementing CE, some companies are reported to have gained up to $60 \%$ reduction in time to market, up to $50 \%$ reduction in life cycle costs and a maximum $95 \%$ of reduction in engineering change demands [6]. Product development has been an essential activity for the success of product competition especially in the fast-growing and fierce competitive arena of the automotive industry [7-9]. The focus of PD research in the automotive industry is directed towards developing and implementing 
lightweight, high strength materials, having as their main objectives to improve vehicle performance, increase fuel efficiency, reduce vehicle emissions and increase vehicle safety at competitive costs $[9,10]$. Among the advanced materials which fall into this category are metal matrix composites (MMCs) [11-14].

In product development related cases, the analytical network process [15] was used by Meade and Presley [16] to select the best option for an R \& D project. Related work by Karsak, Sozer [17] implemented a combination of ANP and QFD to model a systematic decision procedure in product planning. Meanwhile, a study done by Büyüközkan and Feyzıg̃ lu [18] applied ANP-fuzzy to prioritize design requisites by considering the degree of dependence between the customers' needs and the design requirements. ANP is regarded as an algorithm that can cope with all kinds of dependences systematically [19]. It replaces hierarchies with network connections, thus it is implemented for analysis and modeling of the interactions and dependencies among the elements involved in the analysis [20]. In this study, the research objective is to develop a systematic and viable technique to support the simultaneous consideration of all product elements during the analysis phase. Moreover, this technique should carry out an analysis between the product elements which reflects their interaction and relationship. To simulate this technique, it is applied as part of the manufacturing process and material analysis of MMCs for brake disc application.

\section{METHODOLOGY}

This section discusses in detail the concurrent network as part of the new MCDM technique. The CN phase combines CE strategy as indicated in Figure 1. The strategy was applied in a generic framework for synchronized consideration of information from the product investigation and product specification to obtain the product performance, as explained in detail by Fatchurrohman, Sulaiman [21]. Furthermore, CE was used for decomposition of the product performance into conceptual aspects, namely the manufacturing process and material parameters.

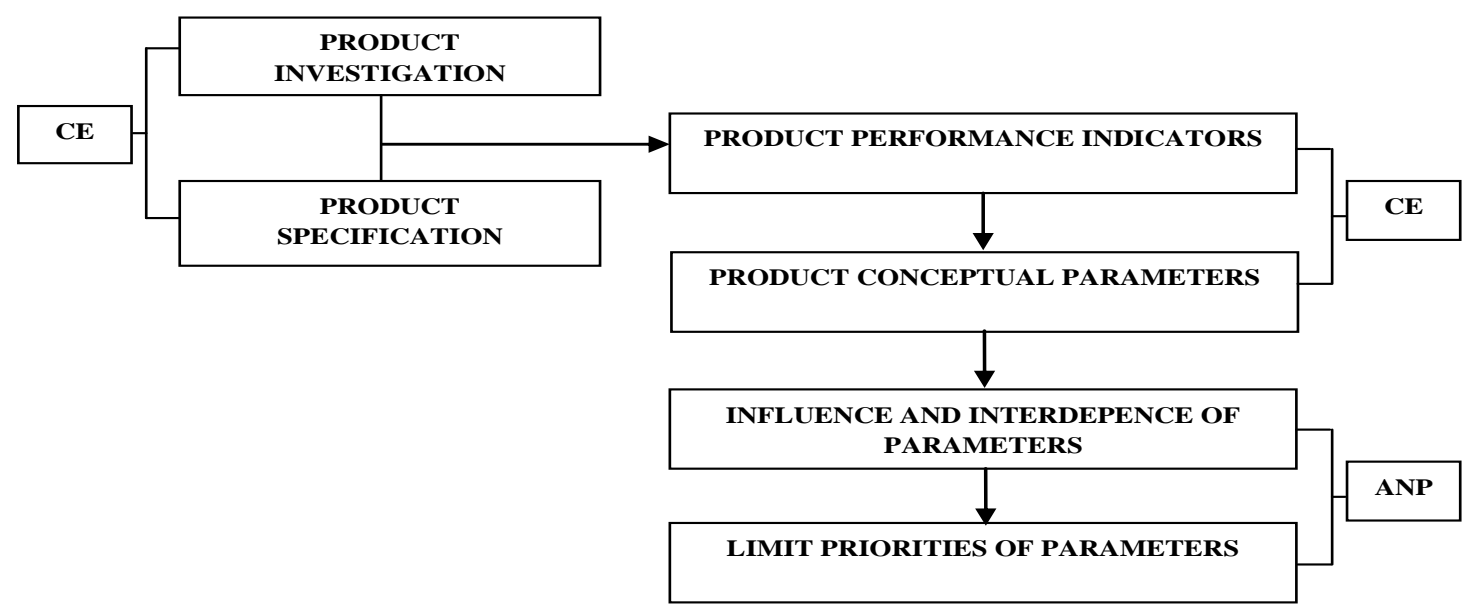

Figure 1. The work flow of concurrent network

The parameters were linked into a network, in which product performance and design parameters were analyzed and each performance's influence on the conceptual parameters was identified. Then the sub-conceptual parameters were analyzed for their 
interdependence relationships. This was the reason why ANP was used to perform ratings among the various parameters in the conceptual design clusters. Moreover, pairwise comparisons were performed to compare conceptual parameters and subconceptual parameters. The final result from the $\mathrm{CN}$ analysis was the global and local weights for each sub-conceptual parameter. The ANP method involves a number of logarithm steps [22]. Figure 2 explains how these steps were taken to analyze the interactions between the product parameters.

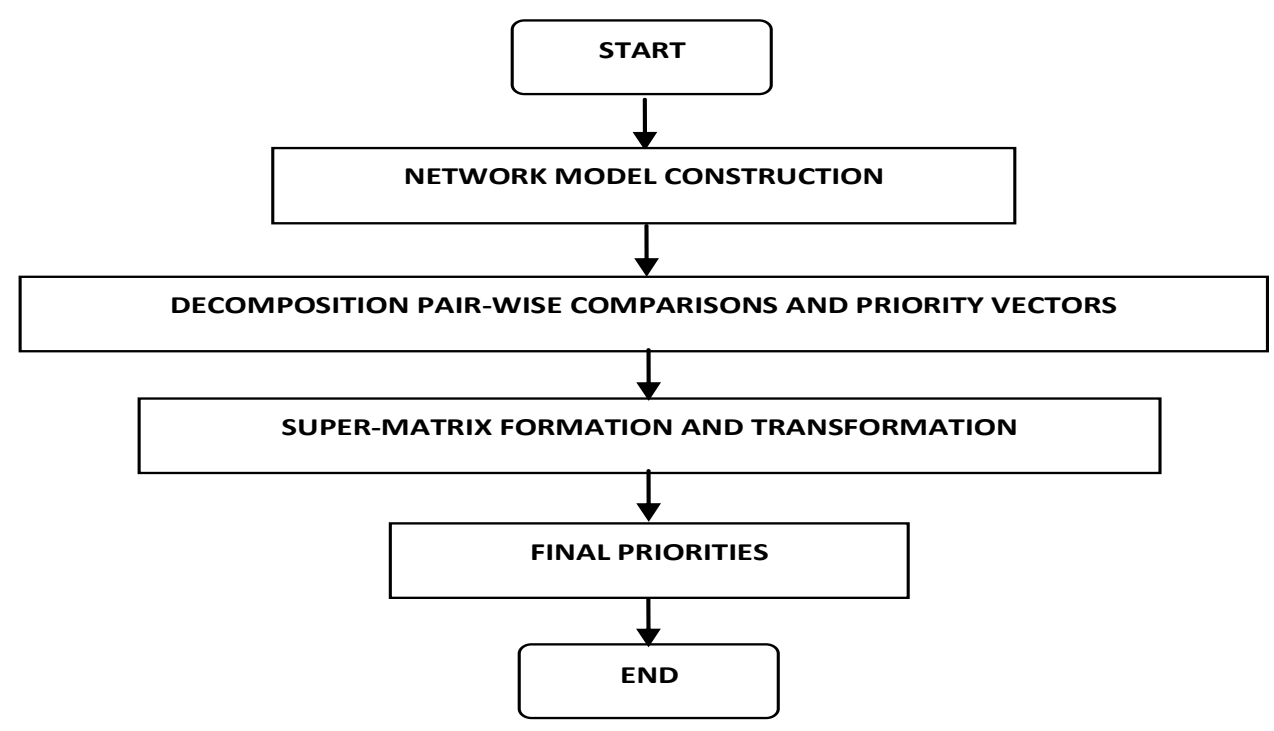

Figure 2. Work flow of analytical network process

The concurrent network starts with network construction to address the relationships between classes and sub-classes which correspond to elements of the conceptual parameters. In the context of $\mathrm{CN}$, the network model consisted of Product, Performance and Conceptual Clusters. Thus, the importance of the clusters was evaluated with respect to their impacts or influences on other clusters. The cluster network was constructed based on the relationships represented in Figure 3.

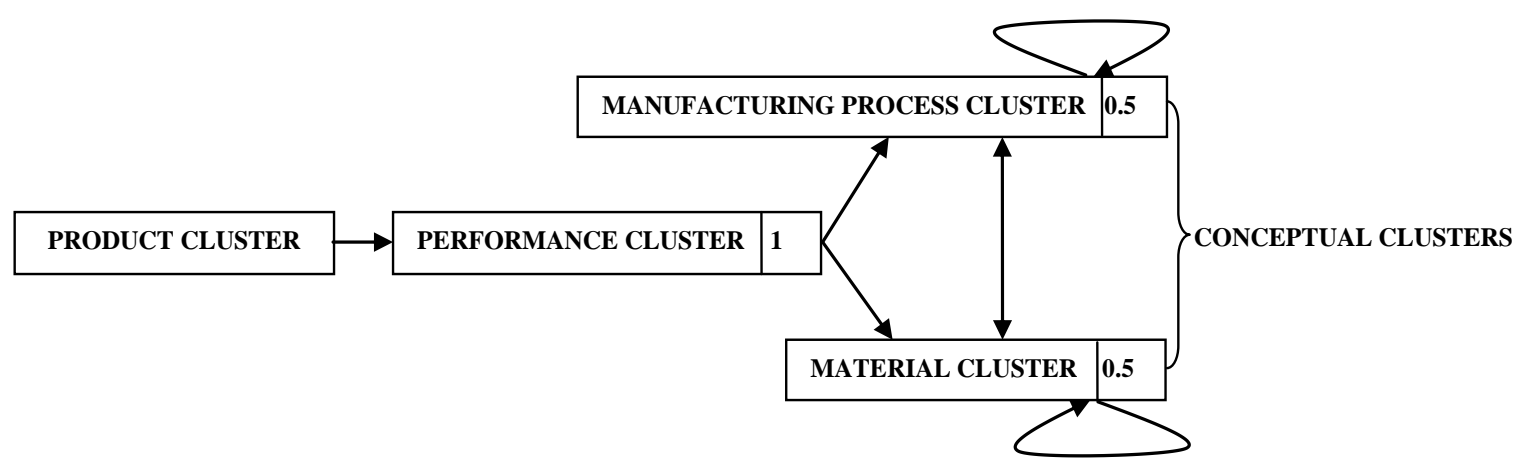

Figure 3. Cluster network with cluster weights.

The product cluster was translated and influenced only by the performance cluster, whereas comparisons were made between conceptual clusters, and in this investigation the conceptual clusters were compared with respect to the performance cluster. It was indicated that the two main conceptual clusters (the manufacturing 
process and material clusters) have the same weight, i.e. 0.5. This means that the conceptual parameter clusters have the same influence on the performance cluster. Analysis of parameters within the cluster was related to an outer dependence, where parameters in a cluster can depend on parameters from another cluster. Outer dependencies are represented by two-way connector arrows; thus, parameters in a cluster can influence the parameters in another cluster and vice versa [23]. Inner dependence refers to the condition when parameters of a cluster influence each other [24]. In the network (Figure 4), the outer dependencies are represented by two-way arrows and the inner dependencies by looped arcs.

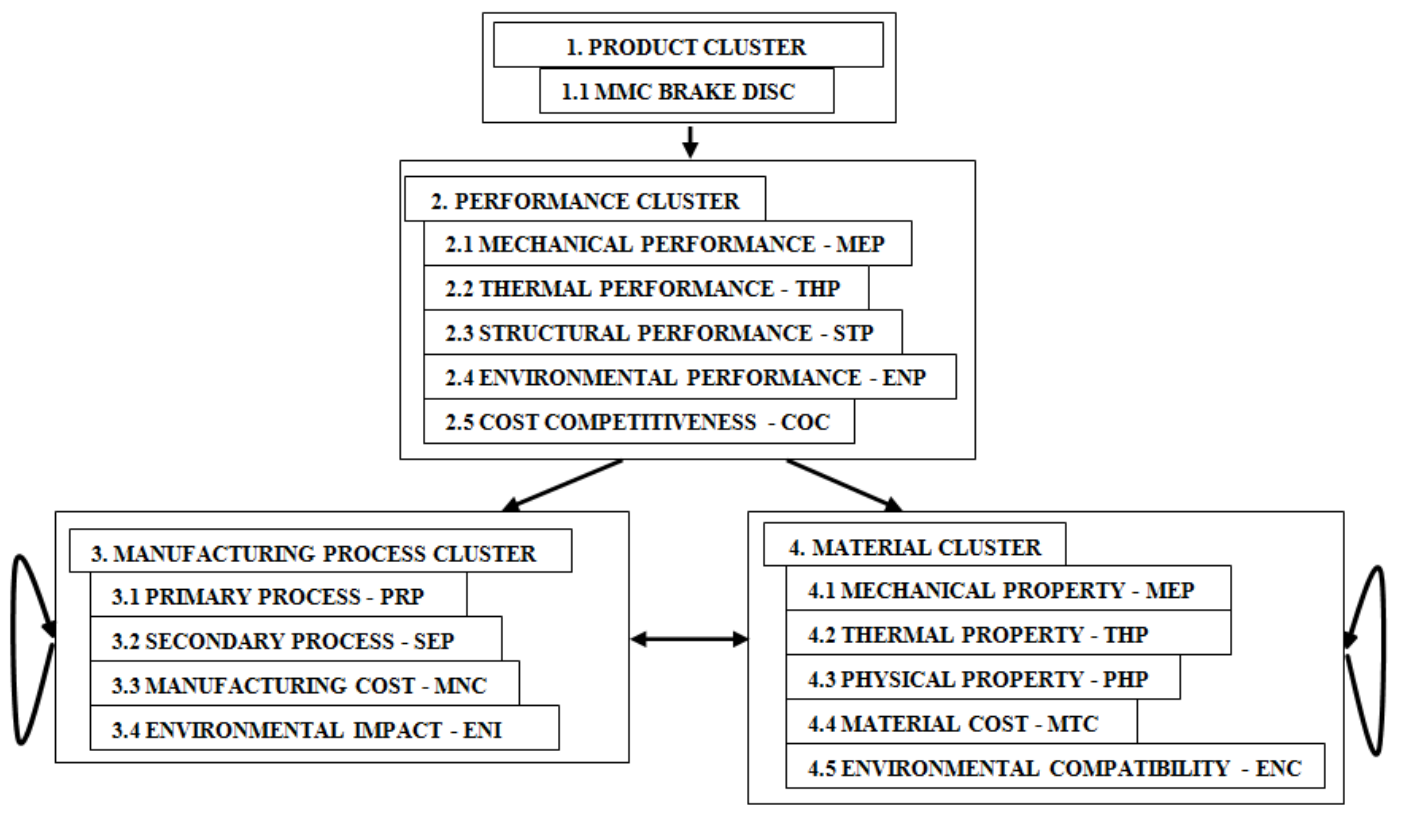

Figure 4. Cluster network with conceptual parameters

\section{RESULTS AND DISCUSSION}

\section{Unweighted Supermatrix}

A supermatrix is a two-dimensional matrix of elements comprising elements under the manufacturing process and material conceptual clusters. The supermatrix was produced from the pair-wise comparison matrices of interdependencies and it represents the effects of the interdependence that exists between the elements in the network [25]. The unweighted supermatrix (USM) in Table 1 contains the result from the pair-wise comparison of all elements for each individual cluster throughout the network, and the number of comparisons was defined by the number (non-zero) of values in the USM. The first column A reflects the priorities of the product performance parameters with regard to the goal. The thermal performance had the highest priority with a score of 0.2123 , and this was followed by mechanical performance (MEP), structural performance (STP), environmental performance (ENP), all having the same priority of 0.1996 , and finally cost competitiveness [26] with a score of 0.1889 . 
Table 1. Unweighted supermatrix.

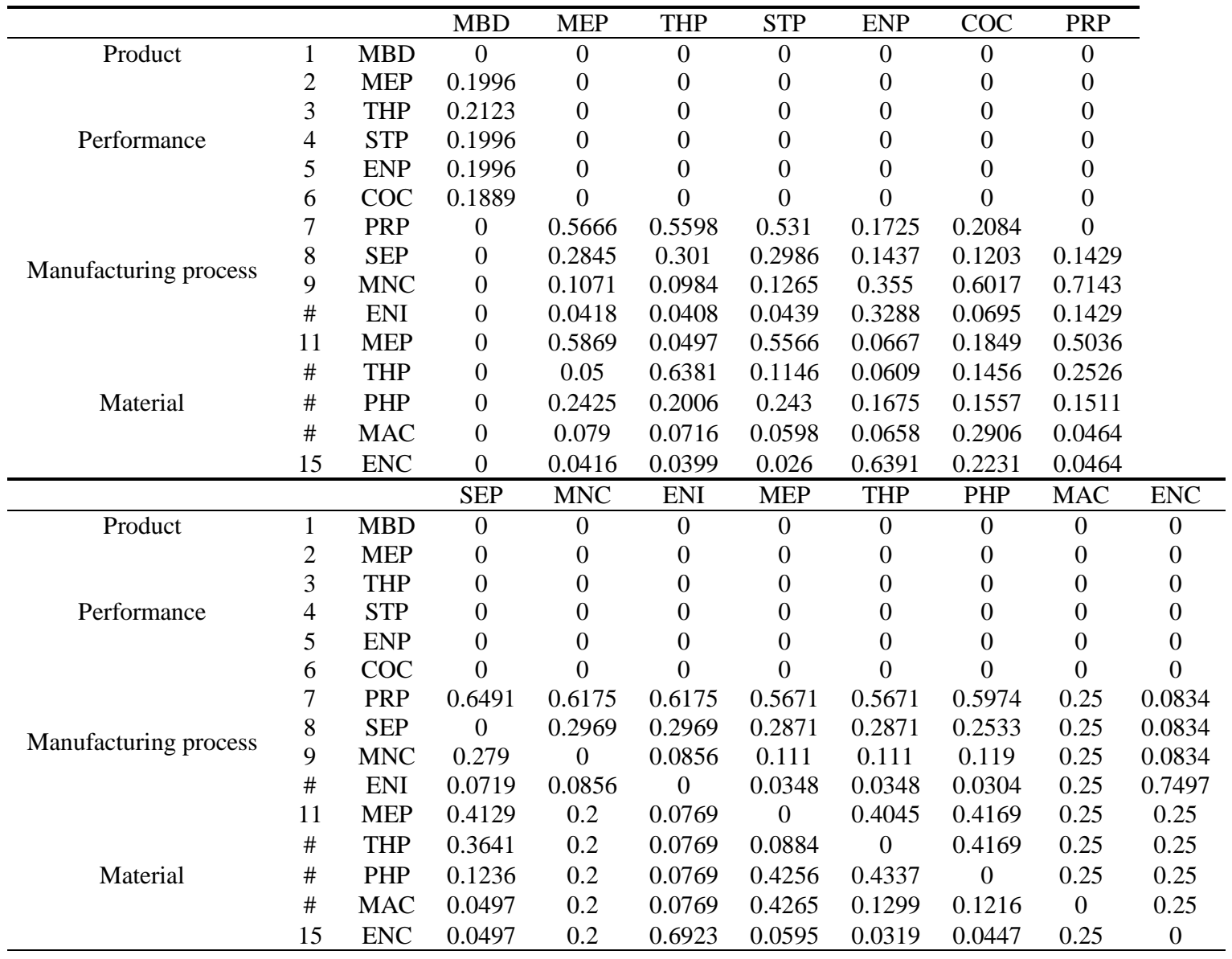

The following section of the USM refers to the manufacturing process cluster's local priorities. For instance, the sub-conceptual parameters of the primary process (PRP), secondary process (SEP), manufacturing cost (MNC) and environmental impact (ENI) with respect to mechanical performance (MEP) were 0.5666, 0.2845, 0.1071, and 0.0418 . This indicates that the primary process (PRP) was more significant for the other sub-conceptual parameters in regard to the mechanical performance (MEP), and then the next priorities were followed by the secondary process (SEP), manufacturing cost (MNC) and environmental impact (ENI). The priorities of other relationships between the manufacturing process parameters and performance parameters are given in columns $\mathrm{B}$ to $\mathrm{F}$ and rows 7 to 10 . For the inner dependence within the manufacturing process cluster, for instance in the case of the manufacturing cost at column I, the inner dependence comparisons of the sub-conceptual parameters refer to the primary process (PRP), secondary process (SEP) and environment impact with respect to manufacturing cost (MNC), and the results were 0.6175, 0.2968, and 0.08563. This means that the primary process (PRP) had a greater effect and was 2.08 times more significant than the secondary process (SEP, and 7.21 times more than the environmental impact. Moreover, the secondary process was 3.47 times more significant than the environmental impact in respect to the manufacturing cost. Meanwhile, the other significance weights of the interrelationships of sub-conceptual parameters within the manufacturing process cluster can be seen in columns $\mathrm{G}$ to $\mathrm{O}$ and rows 7 to 10 .

The relationship between material parameters and performance parameters shows, for instance, the local weights of the sub-conceptual parameters of mechanical 
properties (MEP), thermal properties (THP), physical properties (PHP), material cost (MAC), and environmental compatibility (ENC) with respect to thermal performance with values of $0.0497,0.6386,0.2006,0.0716$, and 0.0399 . This indicates that the mechanical properties have the highest importance and the greatest influence on the thermal performance, followed by the sub-conceptual parameters of thermal properties, physical properties, material cost, and environmental compatibility. The complete set of weights referring to other relationships between material parameters and performance parameters can be seen in columns $\mathrm{B}$ to $\mathrm{F}$ and rows 11 to 15 .

Inside the material cluster, the interrelationships between sub-conceptual parameters were analyzed. For example, in column L - thermal properties, the values represent the importance of mechanical properties, physical properties, material cost, and environmental compatibility with respect to thermal properties. The results in sequence were 0.4045 (MEP), 0.4336 (PHP), 0.1299 and 0.0319 (ENC); this indicates that the physical properties had the highest influence on the thermal properties by 1.072 , 3.338, and 13.59 when compared to the mechanical properties, physical properties, material cost, and environmental compatibility respectively. Next in order of significance in terms of their influence on thermal properties were mechanical properties, material cost and environmental compatibility. The rest of the interdependence relationships within the material cluster are shown in columns $\mathrm{G}$ to $\mathrm{O}$ and rows 11 to 15 .

\section{Weighted Supermatrix}

The next phase involves the transformation of the USM into the weighted supermatrix (WSM) as in Table 2. It was performed by multiplying each element of the USM by the corresponding cluster weight. This was performed in order to obtain the normalized scores for all the elements and is hence able to compare each element to another in terms of its priority. The normalized matrix is achieved when the elements have nonzero numbers and the columns add up to one (i.e. column stochastic), when it is then referred to as the WSM [21]. The first column in the WSM was the same as in the USM, and presents the priorities of the performance parameters in regard to the goal cluster. The priorities which indicate the relationship between the conceptual parameters and performance parameters were presented in normalized weight. For instance, in column $\mathrm{D}$, which refers to structural performance, the rank of the manufacturing process was mostly influenced by the primary process -0.2655 , followed by the secondary process 0.1493 , manufacturing cost -0.0633 and environmental impact -0.0204 . This indicates that the achievement of the structural performance was influenced mostly by the primary process quality and the second most influential was the secondary process. By contrast, in the material conceptual cluster, the most significant parameter influencing the structural performance was mechanical properties with a score of 0.2783 , followed by thermal properties -0.5729 , physical properties -0.1214 , material cost -0.02991 , and the least influential was environmental compatibility -0.01302 . This interpretation can also be applied to columns B to F, rows 7 to 15 .

Meanwhile, the inter-dependence values within the manufacturing process parameters and within the material cluster were also normalized. Hence, for example, under the secondary process column, the sub-conceptual parameter which had the strongest relation was primary process with a priority of 0.3246 , followed by manufacturing cost -0.1395 , and finally environmental impact -0.03597 . In the material cluster, the results can also be analyzed; for instance, the relation under column 
$\mathrm{O}$ - environment compatibility was an interesting result since all the sub-conceptual parameters, i.e. mechanical properties, thermal properties, physical properties and material cost, have the same importance in relation to environmental compatibility with a score of 0.125 . This indicates that the other sub-conceptual parameters under the material cluster have the same degree of influence on environmental compatibility. This understanding is applicable to columns $\mathrm{G}$ to $\mathrm{O}$, rows 7 to 15 .

Table 2. Weighted supermatrix.

\begin{tabular}{|c|c|c|c|c|c|c|c|c|c|c|}
\hline & & & MBD & MEP & THP & STP & ENP & $\mathrm{COC}$ & PRP & SEP \\
\hline \multirow[t]{3}{*}{ Product } & 1 & MBD & 0 & 0 & 0 & 0 & 0 & 0 & 0 & 0 \\
\hline & 2 & MEP & 0.1996 & 0 & 0 & 0 & 0 & 0 & 0 & 0 \\
\hline & 2 & THP & 0.2123 & 0 & 0 & 0 & 0 & 0 & 0 & 0 \\
\hline \multirow[t]{4}{*}{ Performance } & 2 & STP & 0.1996 & 0 & 0 & 0 & 0 & 0 & 0 & 0 \\
\hline & 2 & ENP & 0.1996 & 0 & 0 & 0 & 0 & 0 & 0 & 0 \\
\hline & 3 & $\mathrm{COC}$ & 0.1889 & 0 & 0 & 0 & 0 & 0 & 0 & 0 \\
\hline & 3 & PRP & 0 & 0.2833 & 0.2799 & 0.2655 & 0.0862 & 0.1042 & 0 & 0.3246 \\
\hline \multirow{5}{*}{$\begin{array}{c}\text { Manufacturing } \\
\text { process }\end{array}$} & 3 & SEP & 0 & 0.1423 & 0.1505 & 0.1493 & 0.0719 & 0.0602 & 0.0714 & 0 \\
\hline & 3 & $\mathrm{MNC}$ & 0 & 0.0535 & 0.0492 & 0.0633 & 0.1775 & 0.3009 & 0.3571 & 0.1395 \\
\hline & 3 & ENI & 0 & 0.0209 & 0.0204 & 0.022 & 0.1644 & 0.0347 & 0.0714 & 0.036 \\
\hline & 4 & MEP & 0 & 0.2935 & 0.0249 & 0.2783 & 0.0333 & 0.0925 & 0.2518 & 0.2065 \\
\hline & 4 & THP & 0 & 0.025 & 0.3191 & 0.0573 & 0.0305 & 0.0728 & 0.1263 & 0.1821 \\
\hline \multirow[t]{4}{*}{ Material } & 4 & PHP & 0 & 0.1213 & 0.1003 & 0.1215 & 0.0837 & 0.0779 & 0.0755 & 0.0618 \\
\hline & 4 & MAC & 0 & 0.0395 & 0.0358 & 0.0299 & 0.0329 & 0.1453 & 0.0232 & 0.0248 \\
\hline & 5 & ENC & 0 & 0.0208 & 0.02 & 0.013 & 0.3196 & 0.1116 & 0.0232 & 0.0248 \\
\hline & & & $\mathrm{MNC}$ & ENI & MEP & THP & PHP & MAC & ENC & \\
\hline \multirow[t]{3}{*}{ Product } & 1 & MBD & 0 & 0 & 0 & 0 & 0 & 0 & 0 & \\
\hline & 2 & MEP & 0 & 0 & 0 & 0 & 0 & 0 & 0 & \\
\hline & 2 & THP & 0 & 0 & 0 & 0 & 0 & 0 & 0 & \\
\hline \multirow[t]{4}{*}{ Performance } & 2 & STP & 0 & 0 & 0 & 0 & 0 & 0 & 0 & \\
\hline & 2 & ENP & 0 & 0 & 0 & 0 & 0 & 0 & 0 & \\
\hline & 3 & $\mathrm{COC}$ & 0 & 0 & 0 & 0 & 0 & 0 & 0 & \\
\hline & 3 & PRP & 0.3088 & 0.3088 & 0.2835 & 0.2835 & 0.2987 & 0.125 & 0.0417 & \\
\hline \multirow{5}{*}{$\begin{array}{c}\text { Manufacturing } \\
\text { process }\end{array}$} & 3 & SEP & 0.1484 & 0.1484 & 0.1435 & 0.1435 & 0.1266 & 0.125 & 0.0417 & \\
\hline & 3 & $\mathrm{MNC}$ & 0 & 0.0428 & 0.0555 & 0.0555 & 0.0595 & 0.125 & 0.0417 & \\
\hline & 3 & ENI & 0.0428 & 0 & 0.0174 & 0.0174 & 0.0152 & 0.125 & 0.3749 & \\
\hline & 4 & MEP & 0.1 & 0.0385 & 0 & 0.2023 & 0.2084 & 0.125 & 0.125 & \\
\hline & 4 & THP & 0.1 & 0.0385 & 0.0442 & 0 & 0.2084 & 0.125 & 0.125 & \\
\hline \multirow[t]{3}{*}{ Material } & 4 & PHP & 0.1 & 0.0385 & 0.2128 & 0.2168 & 0 & 0.125 & 0.125 & \\
\hline & 4 & MAC & 0.1 & 0.0385 & 0.2133 & 0.065 & 0.0608 & 0 & 0.125 & \\
\hline & 5 & ENC & 0.1 & 0.3462 & 0.0298 & 0.0159 & 0.0223 & 0.125 & 0 & \\
\hline
\end{tabular}

\section{Limit Centrality}

As the WSM covers the network connections between clusters of product, performance indicator, and conceptual parameters, the final priorities of the manufacturing process parameters and material parameters were ranked and scored for their level of importance. This was done by using the limit centrality table (LCT). The LCT was derived by raising all the values in the WSM to powers by multiplying them by the power $2 k+1$, where $k$ is an arbitrarily large number until it stabilizes. Thus, when the columns of values were the same for every column, the LCT had been attained and the matrix multiplication process was stopped [27]. In this case study, the LCT represents the overall significance of sub-conceptual parameters in terms of their impact and influence on each other and with regard to the performance parameters, taking their 
direct and indirect influences into consideration. The LCT of nine sub-conceptual parameters is specified in Table 3. From this process, the global weights were obtained. Next, the global weights were normalized by cluster weights to obtain the local weights for each element of the sub-conceptual parameters in the network. The value of the local elements is the most important for the next step of the MCDM procedure.

Table 3. Limit centrality of conceptual and sub-conceptual parameters.

\begin{tabular}{cccc}
\hline Concept & Sub-concept & \multicolumn{2}{c}{ Weights } \\
Parameters & Parameters & Global & Local \\
\hline \multirow{3}{*}{$\begin{array}{c}\text { Manufacturing } \\
\text { process }\end{array}$} & SEP & 0.2087 & 0.4175 \\
& MNC & 0.1050 & 0.2101 \\
& ENI & 0.1244 & 0.2489 \\
Material & MEP & 0.0618 & 0.1235 \\
& THP & 0.1501 & 0.3002 \\
& PHP & 0.1065 & 0.2129 \\
& MAC & 0.1089 & 0.2178 \\
& ENC & 0.0752 & 0.1505 \\
& & 0.0593 & 0.1185 \\
\hline
\end{tabular}

In the manufacturing process cluster, the primary process parameter has the highest score, which means that this sub-conceptual parameter was the most important to consider to achieve the required performance of the product. The ranking was followed by manufacturing cost, secondary process and lastly environmental impact. In the material cluster, the ranking was dominated by mechanical properties which was not an expected result since previously the thermal performance had the highest weight. This could be explained by other performance parameters whose achievability relied more on the mechanical properties rather than the other sub-conceptual parameters. The ranking of other sub-conceptual parameters was physical properties followed by thermal properties, material cost and environmental compatibility.

\section{CONCLUSIONS}

In this study $\mathrm{CN}$ was introduced. First, $\mathrm{CE}$ was applied to identify the product performance of an MMCs brake disc and it was defined with five indicators of product performance. These were then decomposed and analyzed into the sub-conceptual parameters of the manufacturing process and material. The dependency and relationship between these parameters were analyzed using the ANP method. The results were indicated in the matrices and in the limit centrality table. The cluster matrix indicated the weights for each cluster. The unweighted supermatrix contained the local priorities and the weighted supermatrix indicated the normalized priorities. Finally, the limit centrality table contained the local and global weights of the sub-conceptual parameters. This study is part of a new MCDM technique, and the local weights of the subconceptual parameters will be implemented in the next stage of the analysis, which is to analyze and obtain the ratings of the technical specifications. 


\section{ACKNOWLEDGEMENTS}

The authors wish to thank to the for Faculty of Manufacturing Engineering, Universiti Malaysia Pahang, 26600 Pekan, Pahang, Malaysia for providing the financial and technical supports (Project No. RDU1403117).

\section{REFERENCES}

[1] Walker P, Rahman SA, Zhang N, Zhan W, Lin Y, Zhu B. Modelling and simulation of a two speed electric vehicle. Sustainable Automotive Technologies. 2012; 193-8.

[2] Bhaskar HB, Sharief A. Effect of solutionizing on dry sliding wear of Al2024Beryl metal matrix composite. Journal of Mechanical Engineering and Sciences. 2012;3:281-90.

[3] Abu Bakar MH, Raja Abdullah RI, Md. Ali MA, Kasim MS, Sulaiman MA, Ahmad SSN, et al. Surface integrity of LM6 aluminum metal matrix composite when machined with high speed steel and uncoated carbide cutting tools. Journal of Mechanical Engineering and Sciences. 2014;6:854-62.

[4] Kayis B, Arndt G, Zhou M, Amornsawadwatana S. A risk mitigation methodology for new product and process design in concurrent engineering projects. CIRP Annals-Manufacturing Technology. 2007;56:167-70.

[5] Tyagi S, Choudhary A, Cai X, Yang K. Value stream mapping to reduce the lead-time of a product development process. International Journal of Production Economics. 2015;160:202-12.

[6] Fine CH, Golany B, Naseraldin H. Modeling tradeoffs in three-dimensional concurrent engineering: a goal programming approach. Journal of Operations Management. 2005;23:389-403.

[7] Porter ME. The five competitive forces that shape strategy. 2008.

[8] Rose ANM, B. Md D, M.N. Ab. R. A Study on Lean Manufacturing Implementation in Malaysian Automotive Component Industry. International Journal of Automotive and Mechanical Engineering. 2013;8:1467-76.

[9] Haniff MHM, Ismail AR, Deros BM, Rahman MNA, Kardigama K. The Taguchi approach in optimizing the environmental factors towards productivity at automotive industry. International Journal of Automotive and Mechanical Engineering. 2011;3:306-17.

[10] Chan BC. The state of the art of electric, hybrid, and fuel cell vehicles. Proceedings of the IEEE. 2007;95:704-18.

[11] Prasad S, Asthana R. Aluminum metal-matrix composites for automotive applications: tribological considerations. Tribology Letters. 2004;17:445-53.

[12] Adebisi AA, Maleque MA, Rahman MM. Metal matrix composite brake rotor: historical development and product life cycle analysis. International Journal of Automotive and Mechanical Engineering. 2011;4:471-80.

[13] Nakanishi H, Kakihara K, Nakayama A, Murayama T. Development of aluminum metal matrix composites (Al-MMC) brake rotor and pad. JSAE Review. 2002;23:365-70.

[14] Sanuddin A, Ali A, Hanim M. Fabrication of Al/Al2O3 FGM rotating disc. International Journal of Automotive and Mechanical Engineering. 2012;5:622-9. 
[15] Mardani A, Tabejamaat S, Hassanpour S. Numerical study of CO and CO2 formation in $\mathrm{CH} 4 / \mathrm{H} 2$ blended flame under MILD condition. Combustion and Flame. 2013;160:1636-49.

[16] Meade LM, Presley A. R\&D project selection using the analytic network process. IEEE Transactions on Engineering Management. 2002;49:59-66.

[17] Karsak EE, Sozer S, Alptekin SE. Product planning in quality function deployment using a combined analytic network process and goal programming approach. Computers \& Industrial Engineering. 2003;44:171-90.

[18] Büyüközkan G, Feyzıoglu O. A fuzzy-logic-based decision-making approach for new product development. International Journal of Production Economics. 2004;90:27-45.

[19] Brunetti G, Golob B. A feature-based approach towards an integrated product model including conceptual design information. Computer-Aided Design. 2000;32:877-87.

[20] Ayă̆ Z, özdem r R. An analytic network process-based approach to concept evaluation in a new product development environment. Journal of Engineering Design. 2007;18:209-26.

[21] Fatchurrohman N, Sulaiman S, Sapuan S, Ariffin M, Baharuddin B. Generic framework for conceptual design using concurrent engineering strategy. A Case Study: Advanced Materials Research. 2013; 626:99-108.

[22] Lee H, Kim C, Cho H, Park Y. An ANP-based technology network for identification of core technologies: A case of telecommunication technologies. Expert Systems with Applications. 2009;36:894-908.

[23] Milani A, Shanian A, Lynam C, Scarinci T. An application of the analytic network process in multiple criteria material selection. Materials \& Design. 2013;44:622-32.

[24] Percin S. Using the ANP approach in selecting and benchmarking ERP systems. Benchmarking: An International Journal. 2008;15:630-49.

[25] Saaty TL. Fundamentals of the analytic network process-Dependence and feedback in decision-making with a single network. Journal of Systems Science and Systems Engineering. 2004;13:129-57.

[26] Saintier N, Palin-luc T, Bénabes J, Cocheteux F. Non-local energy based fatigue life calculation method under multiaxial variable amplitude loadings. International Journal of Fatigue. 2013;54:68-83.

[27] Vargas LG. Decision making with the analytic networt process: economic, political, social and technological applications with benefits, opportunities, costs and risks. International Series in Operations Research and Management Science: Springer; 2006. 